\title{
Conscious Sedation for Upper Digestive Endoscopy Performed by Endoscopists
}

\author{
Ana Laura Colle Kauling ${ }^{1}$, Giovani de Figueiredo Locks, TSA ${ }^{2}$, Guilherme Muriano Brunharo ${ }^{3}$, \\ Viriato João Leal da Cunha ${ }^{4}$, Maria Cristina Simões de Almeida, TSA 5
}

Summary: Kauling ALC, Locks GF, Brunharo GM, Cunha VJL, Almeida MCS - Conscious Sedation for Upper Digestive Endoscopy Performed by Endoscopists.

Background and objectives: Conscious sedation in the ambulatory setting albeit common is not risk-free. The present study aimed at evaluating the blood pressure, heart rate and peripheral oxygen saturation in patients submitted to conscious sedation for upper digestive endoscopy performed by endoscopists.

Methods: A total of 105 patients of both sexes were selected, aged 18 and older, physical status ASA I to III, submitted to upper digestive endoscopy under conscious sedation. The patients were monitored through noninvasive blood pressure measurements, pulse oximetry and heart rate recorded before, during and after the examination. The sedation was carried out with midazolam or meperidine.

Results: The variations in oxygen saturation, blood pressure and heart rate throughout time were not statistically significant. However, an incidence of hypoxia of $41.9 \%$ was observed; $53.3 \%$ of the cases presented arterial hypotension and $25.6 \%$ presented tachycardia. Obese patients were more prone to hypoxia and hypotension than those non obese.

Conclusions: The occurrence of hypoxia and arterial hypotension is common in upper digestive endoscopic examinations under conscious sedation when midazolam and meperidine are associated. Obese patients demonstrated to be more susceptible to hypoxemia and arterial hypotension.

Keywords: COMPLICATIONS: arterial hypertension, hypoxia; DIAGNOSTIC ASSESSMENT; digestive endoscopy; PRE-ANESTHETIC MEDICATION: meperidine, midazolam; SEDATION.

[Rev Bras Anestesiol 2010;60(6): 577-583] CElsevier Editora Ltda.

\section{INTRODUCTION}

In the last decades, the number of minimally-invasive diagnostic procedures has increased considerably 1,2. Even considering the lesser interventionist approach of these procedures, these can cause degrees of discomfort to the patients, which require local anesthesia, moderate sedation or both ${ }^{3}$. The sedation used in upper digestive endoscopic assessments reduces the risks of physical damage to the patient, increase the comfort and collaboration and allows the endoscopists better conditions to perform the examination ${ }^{4}$. Although it is considered a safe practice, conscious sedation is not risk-free ${ }^{3}$.

The aim of the present study was to evaluate the peripheral oxygen saturation $\left(\mathrm{SpO}_{2}\right)$, blood pressure $(\mathrm{BP})$ and heart rate

Received from Universidade Federal de Santa Catarina (UFSC), Florianópolis, SC, Brazil.

1. Physician - UFSC

2. Anesthesiologist - Hospital Universitário - UFSC

3. Medical Student - UFSC

4. Master's Degree Student - Universidade Federal de São Paulo, Professor of the Department of Surgery of UFSC

5. PhD, Johannes Gutenberg/Mainz University - Germany, Assistant Professor of the Department of Surgery of UFSC

Submitted on February 10, 2010

Approved on June 06, 2010

Correspondence to:

Dra. Ana Laura Colle Kauling

Rua Hercílio de Aquino - 319

Jardim Itaguaçu

88085-470 - Florianópolis, SC

E-mail: laurinhakauling@yahoo.com.br
(HR) in patients submitted to conscious sedation for upper digestive endoscopy performed by non-anesthesiologists.

\section{METHOD}

After the study protocol was approved by the local Ethics Committee for Research on Human Subjects and all patients signed the Free and Informed Consent Form, 105 patients, aged 18 and older, of both sexes, physical status ASA I to III were analyzed. The patients had fasted for 12 hours and were electively submitted to an upper gastrointestinal endoscopy (UGE). Pregnant women, nursing women, patients who were intolerant to the study drugs (midazolam and meperidine), patients that presented active digestive bleeding and patients submitted to sedation with other drugs rather than midazolam and meperidine were excluded from the study. The present was a prospective, cross-sectional and observational study.

Upon arrival at the examination room, the patients started to be monitored through the noninvasive measurement of BP in upper limb and $\mathrm{SpO}_{2}$ and $\mathrm{HR}$ though a pulse oximetry. Subsequently, the nursing staff performed local anesthesia of the oropharynx with lidocaine spray at $10 \%$, peripheral vein puncture $n$ upper limb and the patients were placed on left lateral decubitus.

The choice of drugs as well as their doses was made by the examiner, based on the evaluation of the patient's physical status. The drugs used were midazolam and meperidine by intravenous route, with doses varying from 1 to $5 \mathrm{mg}$, and 18 to $30 \mathrm{mg}$, respectively. 
The measurement of $\mathrm{SpO}_{2}$, systolic blood pressure (SBP), diastolic blood pressure (DBP) and heart rate (HR) was carried out at six moments: before the medication, 1 minute, 5 minutes and 10 minutes after the medication, upon patient awakening and 10 minutes after awakening. Interventions such as oxygen supplementation were also recorded.

The oxygen saturation values $\leq 92 \%$ that lasted at least 15 seconds were considered hypoxia. Bradycardia was classified as the measurement of $\mathrm{HR}<60 \mathrm{bpm}$ and tachycardia as the measurement of $\mathrm{HR}>100 \mathrm{bpm}$. Patients that were previously bradycardic or tachycardic were excluded from the HR analysis. Patients were considered hypotensive when there was a decrease in the basal SBP of $20 \%$ or more and, as hypertensive, those presenting an increase in the basal SBP of $20 \%$ or more. Regarding the body mass index (BMI), calculated through the formula $\mathrm{BMI}=$ weight/height $\left(\mathrm{kg} \cdot \mathrm{m}^{-2}\right)$, individuals with $\mathrm{a} \mathrm{BMI} \geq 30 \mathrm{~kg} \cdot \mathrm{m}^{-2}$ were considered obese.

\section{Statistical analysis}

It was estimated that at the hospital where the study was carried out, a total of 2,000 upper digestive examinations were performed each year. A study carried out by Wang and Ling ${ }^{5}$ indicated an incidence of hypoxia of $17 \%$ when midazolam is used for sedation. In the present study, both midazolam and meperidine were used in association for the sedation of patients submitted to UGE. These drugs have an addictive effect as central nervous system depressants. Thus, to detect an increase of $40 \%$ in the incidence of hypoxia, with a confidence level of $95 \%$, a sample size of 105 patients was calculated.

The data were stored and analyzed using a Microsoft Excel spreadsheet, release 7.0 (Seattle, 2003). The level of significance was set at $p<0.05$. Absolute values of frequency and percentage, or means and standard deviations were used to describe the results. To verify the association between the qualitative variables, Fisher's test was used. The analysis of the differences of quantitative variables was carried out using Analysis of Variance (ANOVA).

\section{RESULTS}

Of the 105 assessed patients, most were females with physical status ASA I. Table I summarizes the demographic and physical status data and BMI.

The $\mathrm{SpO}_{2}, \mathrm{BP}$ and $\mathrm{HR}$ values at the previously determined times did not show statistical difference throughout time at the quantitative analysis.

Hypoxia and arterial hypotension were observed in $41.9 \%$ and $53.3 \%$ of the patients respectively whereas $65 \%$ maintained a normal HR (Figures 1, 2 and 3).

The incidence of hypoxia, arterial hypotension and tachycardia was compared by qualitative analysis in different groups. It was observed that obese patients present a higher incidence of hypoxia $(p=0.0032)$ and arterial hypotension $(p=0.0022)$, when compared to non-obese patients.
Table I - Demographic Data of the Studied Population

\begin{tabular}{ll}
\hline Variables & \\
\hline Age (years) * & $47.6 \pm 14.6$ \\
Sex M/F & $63 / 42$ \\
BMI (kg.m-2) * & $25.03 \pm 4.3$ \\
Physical status (ASA) I / II / III & $44 / 27 / 34$ \\
\hline
\end{tabular}

* Values presented as Means \pm SD.

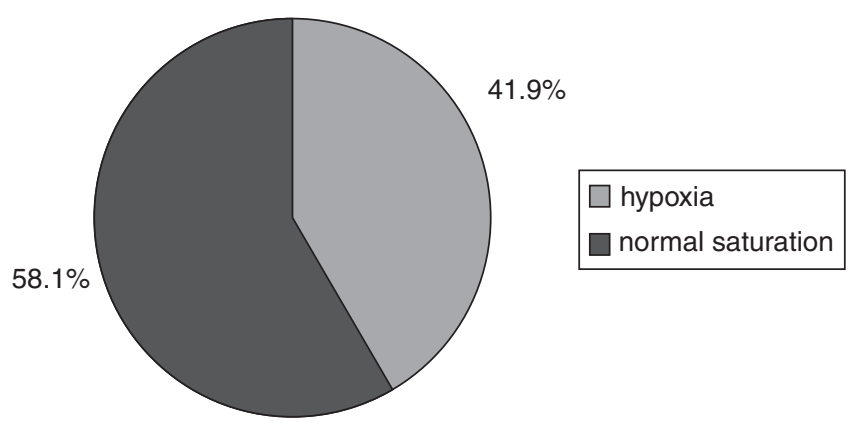

Figure 1 - Incidence of Hypoxia after Sedation.

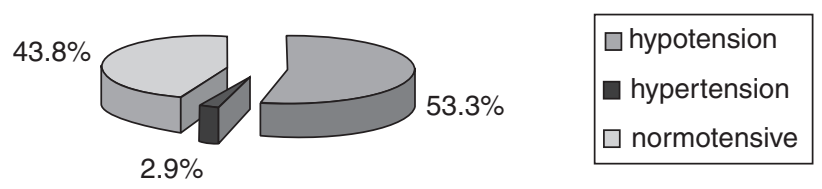

Figure 2 - Incidence of Arterial Hypotension and Arterial Hypertension after Sedation.
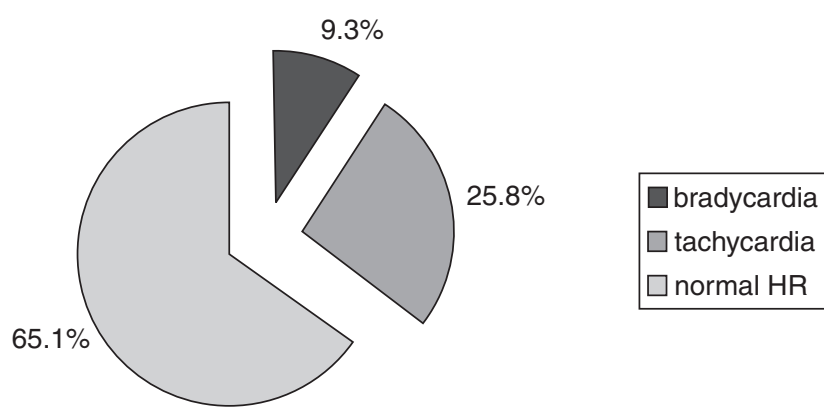

Figure 3 - Incidence of Tachycardia and Bradycardia after Sedation.

Regarding the interventions performed, five patients (4.8\%) received complementary oxygen. The drugs used were midazolam, at a dose of $4.8 \pm 1.0 \mathrm{mg}$ and meperidine at a dose of $29.0 \pm 5.0 \mathrm{mg}$. Of the total of patients, $94.3 \%$ received a combination of meperidine and midazolam. The remaining $5.7 \%$ received only midazolam.

\section{DISCUSSION}

In the present study, the most relevant clinical information observed was the incidence of hypoxia of $41.9 \%$ in upper gastrointestinal endoscopy (UGE) carried out with conscious sedation. According to the literature, it is well established that a decrease in the peripheral oxygen saturation often occurs during UGE, at varying incidences 6 . The use of midazolam as a single anesthetic drug for conscious sedation has been 
analyzed by some studies ${ }^{5,7}$ that demonstrated levels of hypoxemia between $17 \%$ and $30 \%$. The association of midazolam with opioids was carried out by other authors ${ }^{8}$, who observed an incidence of hypoxia of $57 \%$ in their sample, which demonstrates an increase in the incidence of this complication.

In a study carried out with midazolam as single anesthetic drug used for sedation, Patterson et al. ${ }^{9}$ stated that the mechanisms responsible for desaturation result from the action of this drug as a depressant at the respiratory center. It is well established in the literature that the association between benzodiazepines and opioids promotes synergism in their effects with a higher incidence of adverse events $8,10,11$.

Among the patients selected for this study, five received only midazolam at the sedation. The choice of drugs as well as of their doses was made by the examiner, based on his or her assessment of the patient. It is well-known that the association between opioids and benzodiazepines is a synergic one, as described, which might have underestimated the results obtained in relation to the data of clinical relevance - alterations in $\mathrm{SpO}_{2}$ values, $\mathrm{BP}$ levels and $\mathrm{HR}$.

Thus, it is noteworthy the fact that the values obtained on the incidence of hypoxia might fall short of the expected ones for a homogenous sample.

The present study showed that the obese patients presented a significantly higher percentage of hypoxemia. Studies have demonstrated that the respiratory system is markedly affected by obesity due to mechanical and pulmonary alterations ${ }^{12}$, resulting in a significant decrease in the functional residual capacity, the expiratory reserve volume and total pulmonary capacity ${ }^{13}$.

In addition to increasing the risks of hypoxemia, the administration of midazolam can decrease the patients' tensional levels ${ }^{14}$, which is justified by the decrease in the systemic vascular resistance ${ }^{15,16}$. In the present study, an incidence of arterial hypotension of $53.3 \%$ was observed.

Nevertheless, regarding the data obtained on arterial hypotension, it is necessary to emphasize that the break in the standardization of the sample with five patients that received only midazolam might have underestimated the results of this complication.

Similarly to what occurs with the risk of hypoxemia, obese patients demonstrated to be more susceptible to arterial hypotension, presenting higher rates of this complication when compared to nonobese patients $(p=0.0021)$. Although the association between the drugs used in the present study and their hypotensive action ${ }^{14-17}$ is well-established in the literature, no similar protocol was found that would establish a specific association between obesity and hypotension.

The upper gastrointestinal endoscopy is often accompanied by tachycardia ${ }^{18}$, suggested by occurrence of an endocrine response to the stress caused by the examination ${ }^{19}$. In the present study the incidence of tachycardia was $25.6 \%$, a similar incidence to that reported in the literature ${ }^{14,18}$. In an interesting study ${ }^{14}$, the authors compared groups submitted to UGE under sedation and without sedation and recorded the presence of tachycardia in both groups, with the observation that incidence was lower in the group that used midazolam in the sedation, suggesting that this drug works well as a protection against this complication.

The choice of associating midazolam with meperidine for sedation in UGE is carried out more often in the United States ${ }^{20}$ whereas in Europe benzodiazepines are more commonly used ${ }^{21}$.

During the period of sample collection, the variations regarding the choice of drugs for sedation became apparent, according to the assessment of the endoscopists, which characterized the sample as heterogeneous. A predominance of the concomitant use of midazolam and meperidine in bolus was observed. However, as it can be verified in the results of the present study, there are cases in which the physician chooses to use only the benzodiazepine, with the dose being at his or her discretion.

Oxygen supplementation was administered to five patients. The criterion adopted for this intervention was $\mathrm{SpO}_{2}$ value $\leq$ $85 \%$. All patients recovered normal $\mathrm{SpO}_{2}$ values after the supplementation. In a review article on the practice of conscious sedation, it was considered that levels of saturation $<85 \%$ are potentially harmful, which suggests that the use of supplementary oxygen as routine can reduce this risk ${ }^{22}$.

According to the guidelines published by the American Society of Anesthesiologists on sedation carried out by nonanesthesiologists ${ }^{23}$, the equipment used for supplementary oxygen administration must be present when the sedation is carried out and in case of hypoxia the supplementary oxygen must be administrated.

Considering the significant percentage of adverse events that occurred with the use of benzodiazepines associated with opioids, recent studies ${ }^{10,24,25}$ have suggested the administration of propofol (2,6-diisopropylphenol) as the agent of choice for conscious sedation. Recent studies, with samples that include a large number of patients, present as advantage associated with the use of propofol a lower incidence of hypoxemia, varying from $2 \%$ to $5 \%{ }^{26,27}$. Regarding the rates of arterial hypotension, the results also demonstrate a decrease in the number of occurrences, with incidences varying from $7 \%$ to $14 \%$ of the cases ${ }^{26,28}$. Additionally, studies have assessed patient compliance regarding the sedation carried out with propofol in relation to previous sedation experiences with benzodiazepines and opioids and verified high rates of satisfaction 29

In spite of the benefits that conscious sedation brings to both the endoscopist and the patient during the examination, it is not a risk-free procedure.

The data of the present study suggest that it is necessary to give special attention to the group of obese patients when choosing the midazolam-meperidine association for sedation. Although the present study did not observe statistical differences of significant alterations in the levels of $\mathrm{SpO}_{2}, \mathrm{BP}$ and $\mathrm{HR}$ throughout time, one cannot underestimate their clinical importance, mainly regarding hypoxemia.

In a study carried out with a standardized sample in relation to the sedation employed, it is likely that even more relevant clinical data will be obtained regarding the complications, which makes the careful follow-up of sedation at the ambulatory setting of utmost importance, in order to provide more safety and comfort to the patient, as well as to the examiner. 


\section{REFERÊNCIAS / REFERENCES}

01. Owings MF, Kozak LJ - Ambulatory and inpatient procedures in the United States, 1996. Vital Health Stat 13,1998;(139):1-119.

02. Deckert D, Zecha-Stallinger A, Haas T et al. - Anesthesie ausserhalb des Zentral-OP. Anaesthesist, 2007;56:1028-1030, 1032-1037.

03. Fanning RM - Monitoring during sedation given by non-anaesthetic doctors. Anaesthesia, 2008;63:370-374.

04. Cohen LB, Delegge MH, Aisenberg J et al. - AGA Institute review of endoscopic sedation. Gastroenterology, 2007;133:675-701.

05. Wang CY, Ling LC, Cardosa MS et al. - Hypoxia during upper gastrointestinal endoscopy with and without sedation and the effect of preoxygenation on oxygen saturation. Anaesthesia, 2000;55:654-658.

06. Cohen LB - Patient monitoring during gastrointestinal endoscopy: why, when, and how? Gastrointest Endosc Clin N Am, 2008;18:651-663.

07. Allgayer $\mathrm{H}$, Pohl C, Kruis $\mathrm{W}$ - Arterial oxygen desaturation during endoscopic ultrasonography combined with gastroscopy: a safety evaluation in out-patients. Endoscopy, 1999;31:447-451.

08. Patel S, Vargo JJ, Khandwala F et al. - Deep sedation occurs frequently during elective endoscopy with meperidine and midazolam. Am J Gastroenterol, 2005;100:2689-2695.

09. Patterson KW, Noonan N, Keeling NW et al. - Hypoxemia during outpatient gastrointestinal endoscopy: the effects of sedation and supplemental oxygen. J Clin Anesth, 1995;7:136-140.

10. Rex DK - Review article: moderate sedation for endoscopy: sedation regimens for non-anaesthesiologists. Aliment Pharmacol Ther, 2006;24:163-171.

11. Lichtenstein DR, Jagannath $\mathrm{S}$, Baron TH et al. - Sedation and anesthesia in Gl endoscopy. Gastrointest Endosc, 2008;68:815-826.

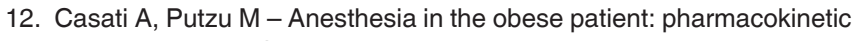
considerations. J Clin Anesth, 2005;17:134-145.

13. Cheah MH, Kam PC - Obesity: basic science and medical aspects relevant to anaesthetists. Anaesthesia, 2005;60:1009-1021.

14. Ristikankare M, Julkunen R, Heikkinen $M$ et al. - Sedation, topical pharyngeal anesthesia and cardiorespiratory safety during gastroscopy. J Clin Gastroenterol, 2006;40:899-905.

15. Young CC, Prielipp RC - Benzodiazepines in the intensive care unit. Crit Care Clin, 2001;17:843-862.

16. Horn E, Nesbit SA - Pharmacology and pharmacokinetics of sedatives and analgesics. Gastrointest Endosc Clin N Am, 2004;14:247-268.

17. Oliveira Filho GR, Turazzi Filho J, Owczarzak Júnior D et al. - Efeitos circulatórios da associação de baixas doses de fentanil ao midazolam durante a indução anestésica e intubação traqueal. Rev Bras Anestesiol, 1990;40:395-399.

18. Osinaike BB, Akere A, Olajumoke TO et al. - Cardiorespiratory changes during upper gastrointestinal endoscopy. Afr Health Sci, 2007;7(2):115-119.

19. Yetkin G, Oba S, Uludag M et al. - Effects of sedation during upper gastrointestinal endoscopy on endocrine response and cardiorespiratory function. Braz J Med Biol Res, 2007;40:1647-1652.

20. Cohen LB, Wecsler JS, Gaetano JN et al. - Endoscopic sedation in the United States: results from a nationwide survey. Am J Gastroenterol, 2006;101:967-974.
21. Quine MA, Bell GD, McCloy RF et al. - Prospective audit of upper gastrointestinal endoscopy in two regions of England: safety, staffing, and sedation methods. Gut, 1995;36:462-467.

22. Bell GD - Premedication, preparation, and surveillance. Endoscopy, 2000;32:92-100.

23. American Society of Anesthesiologists Task Force on Sedation and Analgesia by Non-Anesthesiologists - Practice guidelines for sedation and analgesia by non-anesthesiologists. Anesthesiology, 2002;96:1004-1017.

24. Bryson EO, Sejpal D - Anesthesia in remote locations: radiology and beyond, international anesthesiology clinics: gastroenterology: endoscopy, colonoscopy, and ERCP. Int Anesthesiol Clin, 2009;47:69-80.

25. Bittinger $\mathrm{M}$, Forst $\mathrm{H}$, MessmanN H - Propofol in der gastroenterologischen Endoskopie - Zeit für einen Paradigmenwechsel? Z Gastroenterol, 2004;42:470-474.

26. Heuss LT, Schnieper P, Drewe J et al. - Risk stratification and safe administration of propofol by registered nurses supervised by the gastroenterologist: a prospective observational study of more than 2000 cases. Gastrointest Endosc, 2003;57:664-671.

27. Heuss LT, Schnieper P, Drewe J et al. - Conscious sedation with propofol in elderly patients: a prospective evaluation. Aliment Pharmacol Ther 2003;17:1493-1501.

28. Kulling D, Rothenbuhler R, Inauen W - Safety of nonanesthetist sedation with propofol for outpatient colonoscopy and esophagogastroduodenoscopy. Endoscopy, 2003;35:679-682.

29. Walker JA, McIntyre RD, Schleinitz PF et al. - Nurse-administered propofol sedation without anesthesia specialists in 9152 endoscopic cases in an ambulatory surgery center. Am J Gastroenterol, 2003;98:1744-1750.

Resumen: Kauling ALC, Locks GF, Brunharo GM, Cunha VJL, Almeida MCS - Sedación Consciente para la Endoscopia Digestiva alta Realizada por Médicos Endoscopistas.

Justificativa y objetivos: La sedación consciente en la práctica ambulatorial, aunque sea algo común, no está exenta de riesgos. Este trabajo tuvo el objetivo de evaluar la presión arterial, la frecuencia cardíaca y la saturación periférica del oxígeno en pacientes sometidos a la sedación consciente para la endoscopia digestiva alta, realizada por médicos endoscopistas.

Métodos: Se seleccionaron 105 pacientes de los dos sexos, con una edad mínima de 18 años, estado físico ASA I a III, sometidos a la endoscopia digestiva alta bajo sedación consciente. Los pacientes fueron monitorizados con medidas de presión arterial no invasiva, oximetría de pulso y frecuencia cardíaca registradas anteriormente, durante y después del examen. La sedación fue administrada con los fármacos midazolam y/o meperidina.

Resultados: Las variaciones de saturación de oxígeno, presión arterial y frecuencia cardíaca a lo largo del procedimiento, no fueron estadísticamente significativas, pero se observó la incidencia de hipoxia en un $41,9 \%$. En un $53,3 \%$ de los casos, se registró hipotensión arterial y en un $25,6 \%$, taquicardia. Los pacientes obesos fueron más susceptibles a la hipoxia y a la hipotensión que los pacientes no obesos.

Conclusiones: La incidencia de hipoxia e hipotensión arterial es algo común en los exámenes de endoscopia digestiva alta bajo sedación consciente cuando están asociados al midazolam y a la meperidina. Los pacientes obesos fueron más susceptibles a la hipoxemia y a la hipotensión arterial. 